\title{
RELATIONAL HEALTH, ATTACHMENT, AND PSYCHOLOGICAL DISTRESS IN COLLEGE WOMEN AND MEN
}

\author{
Lisa L. Frey, Denise Beesley, and Merle R. Miller \\ University of Oklahoma
}

\begin{abstract}
This study examines relational health, parental attachment, and psychological distress in college men and women from the perspective of the relational-cultural model (Jordan, Kaplan, Miller, Stiver, \& Surrey, 1991; Miller, 1984). Peer, mentor, and community relationships, as well as secure parental attachment and year in school, were hypothesized to predict psychological distress, although predictive patterns were expected to differ in women and men. Overall, results supported the hypotheses. Secure parental attachment predicted decreased distress for both women and men. Authentic, empowered, and engaged community relationships significantly predicted decreased distress for women and men. However, for women, peer relational quality was also a significant predictor. The relational-cultural model, which suggests that differentiation and the "felt sense of self" (Jordan, 1997, p. 15) evolve through meaningful connections with others rather than as a result of the separation-individuation process, is applied as a framework for interpreting the findings.
\end{abstract}

A substantial body of research on college student adjustment has been amassed over the past several years. A considerable amount of this literature has focused on the relationship between social support and psychological adjustment. Although the research initially emphasized the structure (i.e., type of relationships) and function (i.e., types of available resources) of social support (Shumaker \& Hill, 1991), over time it has expanded to include investigation of the associations between relational health and psychological adjustment (e.g., Berger, 1997; Frey, Tobin, \& Beesley, 2004; Hagerty, Williams, Coyne, \& Early, 1996; Lee, Keough, \& Sexton, 2002; Pretty, 1990). The focus of this study is to further explore these relationships from the perspective of the relational-cultural model (Jordan et al., 1991; Miller, 1984).

Predictably, undergraduates have been the population of interest for much of this research because of the significant adaptations associated with the transition to college

Lisa L. Frey and Denise Beesley are Assistant Professors in the Department of Educational Psychology at the University of Oklahoma; Merle R. Miller is a doctoral student in the Department of Educational Psychology at the University of Oklahoma.

Address correspondence and reprint requests to: Lisa Frey, University of Oklahoma, Department of Educational Psychology, 820 Van Vleet Oval, Room 321, Norman, OK 73019-2041. E-mail: Melissa.Frey-1@ou.edu (e.g., Beeber, 1999; Chickering, 1969; Moller, Fouladi, McCarthy, \& Hatch, 2003). Several variables have been identified as influencing this transitional adjustment, including dealing with family conflicts (Archer \& Lamnin, 1985; Nicholas, 1996), separation from home (Beeber, 1999; Holmbeck \& Wandrei, 1993), academic demands (Archer \& Lamnin, 1985; Dunkel-Schetter \& Lobel, 1990; Dwyer \& Cummings, 2001), finances (Archer \& Lamnin, 1985; Dunkel-Schetter \& Lobel, 1990), and establishing relationships on the university campus (Archer \& Lamnin, 1985; Beeber, 1999; Dunkel-Schetter \& Lobel, 1990).

Two additional factors that have emerged in the literature as key variables related to psychological adjustment to college are gender (Frey et al., 2004; Lapsley, Rice, \& FitzGerald, 1990; Lee \& Robbins, 2000; Olson \& Shultz, 1994; Stokes \& Levin, 1986; Wohlgemuth \& Betz, 1991) and parental attachment (Fass \& Tubman, 2002; Kalsner \& Pistole, 2003; Kenny \& Rice, 1995; Lapsley et al., 1990; Lopez \& Gormley, 2002; Rice, FitzGerald, Whaley, \& Gibbs, 1995; Mattanah, Hancock, \& Brand, 2004; Vivona, 2000). In addition, differing gender-based interrelationships among attachment, relational quality and preferences, and psychological adjustment have been reported. For instance, in a study investigating the relationships among parent and peer attachment, individuation-separation, and college adjustment, Rice et al. (1995) found that college women, as compared to men, reported greater trust and communication with peers, greater consistency over time 
in peer attachment, and similar associations for parental and peer attachments over time. Kenny and Donaldson (1991) found that college women reported greater parental attachment than men and noted that this greater attachment was significantly associated with higher social competence and psychological well-being for women. In addition, women and men have been found to prefer different relational domains, with men preferring group or community relationships (Frey et al., 2004; Stokes \& Levin, 1986) and women preferring dyadic relationships (Stokes \& Levin, 1986) or both dyadic and community relationships (Frey et al., 2004). Similarly, Lee and Robbins (2000) reported that college women place importance on interdependency and intimacy in social connections, whereas men seek social connection based on power and status in comparison to others. Given these findings, gender and attachment appear to be important variables to consider when investigating college student psychological adjustment.

\section{Relational-Cultural Model and Psychological Distress}

The relational-cultural model (Jordan et al., 1991; Miller, 1984) provides a useful framework through which gender differences in relational patterns can be better understood. The model suggests that differentiation and maturity of the "felt sense of self" (Jordan, 1997, p. 15) evolves through meaningful connections with others rather than as a result of the separation-individuation process, as proposed by traditional models (Miller \& Stiver, 1997). Several theorists and researchers have questioned the applicability of traditional models of separation-individuation to ethnic minorities and women (e.g., Choi, 2002; Gilligan, 1982; Green, 1990; Josselson, 1988). For instance, Choi (2002) found that the level of collectivism, which emphasizes interdependence over independence, was positively related to college adjustment in Korean American students and suggested that "the theoretical view that healthy psychological development results from higher levels of independence and separation should be re-examined for the general population of college students as well as for ethnic minority populations" (p. 473). Similarly, Walker (2004) observed that when separation and individuation are accepted as the standard for psychological health and maturity, the developmental experiences and cultural worldviews of many groups and individuals are marginalized and pathologized.

According to the relational-cultural model, the four core aspects of growth-enhancing relationships include: (a) mutual engagement, defined as mutual involvement, commitment, and sensitivity to the relationship; (b) authenticity, defined as the freedom to be genuine in the relationship; (c) empowerment, defined as the capacity for action and sense of personal strength that emerges from the relationship; and (d) the ability to deal with conflict, defined as the ability to express, receive, and process diversity in the relationship (Liang, Tracy, Taylor, \& Williams, 2002a). A chronic absence of these qualities in relationships results in a lack of interpersonal connection and a sense of isolation leading to psychological distress (Jordan \& Dooley, 2001; Walker, 2004).

The relational-cultural model proposes that Western sociocultural influences impact the unfolding of the developmental process for women and men (Bergman, 1991; Miller, 1991; Walker, 2004). Sociocultural influences are conceptualized as both reinforcing and devaluing women's relational skills and sense of responsibility for relationships (Miller, 1991), thus placing women in the position of functioning as relational caretakers (Gilligan, 1982; Green, 1990; Miller, 1986), a role that is essential but "treated almost as if it doesn't exist, or only important enough for women to do" (Miller, 1986, p. 75). In contrast, sociocultural influences shape men to develop their identity and self-esteem through a process of competition or comparison with others at the expense of relational development (Bergman, 1991). The point is not to idealize women (Miller \& Stiver, 1997) but to recognize that difference can be construed in a manner that perpetuates inequities and to underscore the cost to society and all individuals of rigidly imposed gender role standards. For instance, men may learn to sacrifice relational skill development to feel special and unique (Bergman, 1991), whereas women may learn to sacrifice authenticity to maintain relationships (Brown \& Gilligan, 1992; Miller, 1991).

\section{Relational-Cultural Model, Relational Quality, and Attachment}

Attachment theory emphasizes the role of the parent-child relationship in providing the child with an internal template for participating in relationships that influence individuals over the life span (Ainsworth, Blehar, Walters, \& Wally, 1978; Bowlby, 1982). Thus, parental attachment has been conceptualized as having a continuing impact on the adjustment of young adults during the transition from home to college. Similarly, the relational-cultural model hypothesizes that "relational images" (Miller \& Stiver, 1997, p. 40), templates for relationships that originate in childhood and are elaborated over time, provide a framework through which individuals attribute meaning to their relational patterns and develop a sense of relational competence (Miller \& Stiver, 1997; Walker, 2004).

There is, however, a significant theoretical difference between attachment theory and the relational-cultural model in their conceptualizations of attachment relationships. Although some attachment scholars emphasize the value of connection and authenticity in relationships throughout the life span (e.g., Allison \& Sabatelli, 1988; Kenny \& Rice, 1995), the function of relationships is to promote and support individuation, separation, and autonomy. For example, Kenny and Rice (1995) state that “... the attachment model recognizes the importance of both connection and support for autonomy in promoting psychological growth and adaptive functioning ..." (p. 435, emphasis added). Likewise, 
Allison and Sabatelli (1988) point to the role of relationships with others as one dimension of individuation. The relational-cultural model, on the other hand, conceptualizes the "felt sense of self" (Jordan, 1997, p. 15) as embedded in the relational self:

... [T] he deepest sense of one's being is continuously formed in connection with others and is inextricably tied to relational movement. The primary feature, rather than structure marked by separateness and autonomy, is increasing empathic responsiveness in the context of interpersonal mutuality (Jordan, 1997, p. 15).

\section{Hypotheses}

Based on the relational-cultural framework, some assumptions can be made regarding the associations among relational health, parental attachment, and psychological distress in women and men. First, it is implied that the lack of growth-enhancing qualities in relationships leads to psychological distress. This assumption is in contrast to the view that it is psychological distress that leads to impaired quality of social relationships. Second, it suggests that relational quality will have an impact on psychological functioning beyond the influence that can be attributed to secure parental attachment. Although relational images are influenced by early childhood experiences with parents, they continue to elaborate throughout the life span as individuals develop social and other intimate relationships outside the family (Miller \& Stiver, 1997). Thus, relational images impact the sense of relational self in an oscillating rather than linear fashion (Surrey, 1991). Consequently, parental attachment as an indicator of enduring attachment security is conceptualized as important but not sufficient in investigating the association between relational health and psychological adjustment. Last, the model suggests a different framework for understanding gendered patterns in relational networks. More specifically, women and men may have learned to seek connectedness within different relational domains (e.g., dyadic peer relationships versus group or community affiliation).

The purpose of the current study was to explore the associations among relational patterns, attachment, and psychological distress in college women and men from the perspective of the relational-cultural model. Specifically, it was hypothesized that (a) peer, mentor, and community relational health and secure parental attachment would predict lower psychological distress in women and men; (b) peer, mentor, and community relational health would predict lower psychological distress in women and men beyond that predicted by secure parental attachment; and (c) women and men would show different predictive patterns in regard to peer, mentor, and community relational health and psychological distress, with quality of peer relationships being a significant predictor in females and quality of community relationships being a significant predictor in males.

\section{METHOD}

\section{Participants}

The study was conducted at a large (enrollment approximately 25,000), state-funded Midwestern university where, during the 2004/2005 academic year, approximately $48 \%$ of undergraduates received need-based financial aid. A total of 245 undergraduate students $($ female $=131 ;$ male $=114$ ) participated in the study. The mean age of female and male participants was similar, 20.84 and 20.21 years, respectively, as was their year in school (female $M=2.3$; male $M=2.1$ ). Overall, $65 \%$ reported being freshmen or sophomores and $34 \%$ reported being juniors or seniors. The participants' ethnicities were also similar. Overall, $80 \%$ of the participants identified as European American/White, 2\% as Hispanic American, $2 \%$ as Asian American, $5 \%$ as African American, $7 \%$ as Native American, and $5 \%$ as unidentified/non-White. Two percent of the students reported identifying as gay, lesbian, bisexual, or transgendered. The four top majors were the same for females and males: Arts and Sciences, Business, Pre-professional, and Undeclared, with Arts and Sciences $(36 \%)$ and Undeclared (21\%) constituting the largest categories for the combined participant group. Family income as reported by participants was less than $\$ 35,000$ for $19 \%$ of participants, between $\$ 36,000$ and $\$ 55,000$ or between $\$ 56,000$ and $\$ 75,000$ for $14 \%$ each, and greater than $\$ 75,000$ for $50 \%$, with $3 \%$ not reporting family income. The demographics of study participants were similar to the overall university population in terms of gender and ethnicity.

\section{Instruments}

Outcome Questionnaire 45 (OQ45). Subjective psychological distress was measured by the OQ45 (Lambert, Lunnen, Umphress, Hansen, \& Burlingame, 1994). The self-report scale, which measures a range of symptoms including those associated with depression, anxiety, and stress-related illness (Lambert, Gregersen, \& Burlingame, 2004), consisted of 45 items presented in a 5-point Likert scale ranging from 1 (never) to 5 (almost always). The range of total scores was 45 to 225 , with a higher score indicating that the individual was reporting a higher level of total psychological distress. Three subscales measure symptoms of distress, social-role functioning, and interpersonal difficulties. The subscales were fairly highly correlated $(r=.66$ and above in this study); therefore, the total score rather than the subscale scores was used in the present study. Examples of items include: "I tire quickly" (Symptoms of Distress), "I feel stressed at work/school" (Social-Role Functioning), and "I am concerned about family troubles" (Interpersonal Difficulties).

Cronbach's alpha of .93 and a 3-week test-retest reliability of .84 have been reported for the OQ45 (Lambert et al., 1996). In addition, concurrent validity with related measures has been reported, with correlations ranging from .53 to .66 (Lambert et al., 1996). Normative data for the OQ45 
has been drawn from community, college, and clinical samples across a variety of geographical locations in the United States (Lambert et al., 1996). For this study, the Cronbach's alpha was .94 for women and .90 for men.

Relational Health Indices (RHI). The RHI (Liang et al., $2002 \mathrm{~b}$ ) is a 37 -item self-report scale developed to operationalize three of the four conceptual dimensions of relationship quality outlined by the relational-cultural model: engagement, authenticity, and empowerment. The RHI can be scored in two ways. First, three "composite scores" (Liang et al., 2002b, p. 27) measuring Peer (12 items), Mentor (11 items), and Community (14 items) relationship domains can be obtained (Liang et al., 2002b). Each composite score measures relational quality within that relationship domain. Alternatively, three "subscale scores" (Liang et al., 2002b, p. 27) measuring the relational qualities of engagement, authenticity, and empowerment within each composite score can be calculated (Liang et al., 2002b). Frey, Beesley, and Newman (2005) found, however, a unidimensional structure for the Peer and Mentor composites, and a two-component structure for the Community composite. Consequently, they suggested that the Peer, Community, and Mentor composite scores are most appropriate for measuring overall relational quality within the associated domain. Use of the composite scores also allowed clearer interpretation regarding relational patterns because each score describes a distinct relationship type (e.g., a group focus in Community versus a dyadic focus in Peer; Liang et al., 2002b). Thus, composite scores were used in this study.

The RHI response format is a 5-point Likert scale ranging from 0 (never) to 4 (always). It should be noted that, due to a clerical error, one item was inadvertently omitted from the Mentor subscale for a portion of the study. Because this error resulted in a number of missing values, and in view of the adequate Cronbach's alpha for the abbreviated scale, the decision was made to use the 10-item scale for all study analyses. Thus, in this study, total composite scores ranged from 0 to 48 for Peer, 0 to 40 for Mentor, and 0 to 56 for Community, with higher scores indicating greater relational quality (i.e., greater engagement, authenticity, and empowerment). The directions included definitions for peer, mentor, and community, with community being defined as the college community (Liang et al., 2002b). Examples of items include: "I feel understood by my friend" (Peer); "I can be genuinely myself with my mentor" (Mentor); and "I feel a sense of belonging to this community" (Community).

The RHI has been shown to have acceptable internal consistency with Cronbach's alphas for the composite scores ranging from .85 to .92 (Frey et al., 2005; Frey et al., 2004; Liang et al., 2002b). In addition, correlations of the RHI with related instruments have shown evidence of convergent and concurrent validity (Liang et al., 2002b). For this study, the Cronbach's alphas for women and men, respectively, were .88 and .88 (Peer), .90 and .89 (Mentor), and .89 and .88 (Community).
Although two of the OQ45 subscales also assessed aspects of relationships as related to psychological distress, these subscales had relatively low correlations with the RHI composite scores, suggesting that the instruments differed in what they were measuring. In particular, the RHI measured three dimensions of relational quality, as noted previously, whereas the OQ45 subscales measured functioning within the interpersonal and social-role domains (Lambert et al., 1994).

Parental Attachment Questionnaire (PAQ). Parental attachment was measured by the PAQ (Kenny, 1987). The self-report scale consists of 55 items presented with a 5-point Likert scale ranging from 1 (not at all) to 5 (very much). The range of total scores was 55 to 275 , with higher scores indicating greater overall parental attachment security. Three subscales, Affective Quality of Relationships (27 items), Parents as Facilitators of Independence (14 items), and Parents as Sources of Support (13 items), measure theorized aspects of parental attachment (Kalsner \& Pistole, 2003), and one item contributes to the total PAQ score but was not scored on any subscale (M. Kenny, personal communication, April 6, 2005). However, the PAQ total score as an indicator of overall parental attachment security was of interest to this study. In addition, the Affective Quality subscale was highly correlated with each of the other two subscales $(r=.77$ to .78$)$ for the females in the study, although somewhat lower for males ( $r=.64$ to .53). Similarly, Kenny and Donaldson (1991) reported fairly high correlations between the Affective Quality subscale and each of the remaining subscales ( $r=.66$ to .79$)$. Thus, due to potential multicollinearity concerns when bivariate correlations are at or above .70 (Tabachnick \& Fidell, 1996), the total PAQ score rather than the subscale scores was used for this study. Examples of items include: "In general, my parents are persons I can count on to provide emotional support when I feel troubled" (Affective Quality); "In general, my parents have trust and confidence in me" (Parents as Facilitators of Independence); and "In general, my parents have given me as much attention as I have wanted" (Parents as Sources of Support).

Kenny (1987) reported Cronbach's alphas for the PAQ ranging from .93 to .95 and a 2 -week test-retest reliability of .92. In addition, correlations between the PAQ and similar measures have shown evidence of concurrent and convergent validity (Kenny \& Donaldson, 1991). For this study, the Cronbach's alpha was .96 for women and .92 for men.

\section{Procedures}

The undergraduate students recruited to participate in the study were enrolled in introductory career exploration and anthropology classes. A brief description of the study was read in each class by the instructor or a doctoral-level research assistant. All students in attendance agreed to participate and, after reading an informed consent form, 
the students anonymously completed a packet containing a brief demographic form and instruments. Students who volunteered to participate received a minimal amount of course credit.

\section{Data Analysis for Regression Models}

College women and men were examined separately in hierarchical regression models (Cohen \& Cohen, 1983) to explore the relationship of predictor variables to the criterion variable, OQ45 scores. The model included three predictor variables entered in the order listed: year in school, PAQ, and the three RHI composite scores (i.e., Peer, Mentor, Community). Year in school was entered in the first step and PAQ in the second step to partial out their effects before accounting for the variance explained by the relationship variables. Last, Peer, Mentor, and Community were entered simultaneously to study possible differences in relational patterns in predicting psychological distress.

\section{RESULTS}

Means, standard deviations, effect sizes, and intercorrelations for all measured variables are presented in Table 1 for comparison by gender. The predictor variables were not highly correlated, and correlations between predictor variables and the criterion variable were small to moderate. The means of the PAQ, Peer, and Mentor scores were significantly higher for females as compared to males, with the magnitude of the mean differences in each case at the small to moderate level $\left(r_{\mathrm{pb}}=.22, .23\right.$, and .22 , respectively).

\section{Regression Model: Women}

The adjusted $R^{2}$ explained by the full model was .34 , $F(5,124)=14.22, p<.001$. As shown in Table 2 , the contribution of year in school was not significant. The PAQ explained a significant $15 \%$ of the variance, adjusted $R^{2}=$ $.14, p<.001$. The block of Peer, Mentor, and Community accounted for $22 \%$ of additional variance (adjusted $R^{2}=$ $.34, p<.001)$. The significance was attributable to the Peer and Community scores, with $p<.01$ and .001 , respectively. In summary, for college women, higher levels of psychological distress were significantly predicted by lower levels of parental attachment and decreased levels of peer and community relational health.

\section{Regression Model: Men}

The adjusted $R^{2}$ explained by the full model was .21 , $F(5,107)=7.03, p<.001$. As shown in Table 2 , the contribution of year in school to OQ45 scores was not significant. The PAQ explained a significant $15 \%$ of the variance, adjusted $R^{2}=.15, p=.001$. The block of Peer, Mentor, and Community accounted for an additional $8 \%$ of the variance (adjusted $R^{2}=.21, p=.01$ ). The significance was attributable to Community $(p<.01)$. In summary, for college men, higher levels of psychological distress were significantly predicted by lower levels of parental attachment and decreased levels of community relational health.

\section{Table 1}

Means, Standard Deviations, and Intercorrelations of College Women and Men on Measured Variables

\begin{tabular}{|c|c|c|c|c|c|c|c|c|}
\hline Variable & $M$ & $S D$ & 1 & 2 & 3 & 4 & 5 & 6 \\
\hline \multicolumn{9}{|c|}{ Women $(n=131)$} \\
\hline 1. OQ45 & 95.18 & 21.28 & - & -.01 & $-.39 * *$ & $-.44^{* *}$ & $-.35^{* *}$ & $-.53^{* *}$ \\
\hline 2. Yr in school & 2.32 & .98 & & - & -.01 & .03 & .09 & -.10 \\
\hline 3. PAQ & $212.51^{\mathrm{a}}$ & 35.45 & & & - & $.21^{*}$ & $.44^{* *}$ & $.35^{* *}$ \\
\hline 4. Peer & $38.63^{\mathrm{b}}$ & 7.35 & & & & - & $.35^{* *}$ & $.48^{* *}$ \\
\hline 5. Mentor & $30.66^{\mathrm{c}}$ & 6.32 & & & & & - & $.47^{* *}$ \\
\hline 6. Community & 30.90 & 9.74 & & & & & & - \\
\hline \multicolumn{9}{|l|}{$\operatorname{Men}(n=114)$} \\
\hline 1. OQ45 & 100.00 & 18.37 & - & -.13 & $-.39 * *$ & $-.26^{* *}$ & $-.25^{* *}$ & $-.34^{* *}$ \\
\hline 2. Yr in school & 2.09 & .90 & & - & -.05 & .03 & -.01 & .08 \\
\hline 3. PAQ & $197.80^{\mathrm{a}}$ & 28.65 & & & - & $.26^{* *}$ & $.34^{* *}$ & $.21^{*}$ \\
\hline 4. Peer & $35.28^{\mathrm{b}}$ & 7.13 & & & & - & $.57^{* *}$ & $.37^{* *}$ \\
\hline 5. Mentor & $27.85^{\mathrm{c}}$ & 6.47 & & & & & - & $.34^{* *}$ \\
\hline 6. Community & 29.39 & 8.76 & & & & & & - \\
\hline
\end{tabular}

Note. OQ45 = Outcome Questionnaire 45; higher scores indicate increased psychological distress (range 45 to 225 ). Yr in school = year in college. $\mathrm{PAQ}=$ Parental Attachment Questionnaire; higher scores indicate greater attachment security, and fostered autonomy and emotional support from parent(s) (range 55 to 275). Peer, Mentor, \& Community: Higher scores indicate an increased level of relational health quality (Peer range 0 to 48; Mentor range 0 to 40 ; Community range 0 to 56 ).

${ }^{\mathrm{a}}$ Effect size small to moderate, $r_{\mathrm{pb}}=.22 .{ }^{\mathrm{b}}$ Effect size small to moderate, $r_{\mathrm{pb}}=.23$. ${ }^{\mathrm{c}}$ Effect size small to moderate, $r_{\mathrm{pb}}=.22$. ${ }^{*} p \leq .05 .{ }^{* *} p \leq .01$. 
Table 2

Hierarchical Multiple Regression Analyses for Variables Predicting OQ45 Scores in College Women and Men

\begin{tabular}{|c|c|c|c|c|c|c|c|c|}
\hline Independent Variable & Step & $R^{2}$ & $\Delta R^{2}$ & F Change & $d f$ & $B$ & $S E B$ & $\beta$ \\
\hline \multicolumn{9}{|l|}{ Women $(n=131)$} \\
\hline Yr in school & 1 & .00 & .00 & .02 & $(1,128)$ & -.15 & 1.58 & -.01 \\
\hline PAQ & 2 & .15 & .15 & $22.15^{* * *}$ & $(1,127)$ & -.13 & .05 & $-.21^{* *}$ \\
\hline Peer & 3 & .36 & .22 & $14.03^{* * *}$ & $(5,124)$ & -.66 & .24 & $-.23^{* *}$ \\
\hline Mentor & 3 & & & & & -.07 & .30 & .02 \\
\hline Community & 3 & & & & & -.73 & .20 & $-.34^{* * *}$ \\
\hline \multicolumn{9}{|l|}{$\operatorname{Men}(n=114)$} \\
\hline Yr in school & 1 & .02 & .02 & 1.90 & $(1,111)$ & 2.80 & 1.72 & .14 \\
\hline PAQ & 2 & .16 & .15 & $19.31^{* * *}$ & $(1,110)$ & -.19 & .06 & $-.30^{* * *}$ \\
\hline Peer & 3 & .25 & .08 & $3.97^{* *}$ & $(5,107)$ & -.22 & .27 & -.09 \\
\hline Mentor & 3 & & & & & -.04 & .30 & -.02 \\
\hline Community & 3 & & & & & -.53 & .19 & $-.25^{* *}$ \\
\hline
\end{tabular}

Note. OQ45 = Outcome Questionnaire 45; higher scores indicate increased psychological distress. Yr in school = year in college. PAQ $=$ Parental Attachment Questionnaire; higher scores indicate greater attachment security, and fostered autonomy and emotional support from parent(s). Peer, Mentor, \& Community: Higher scores indicate an increased level of relational health.

${ }^{* *} p<.01 ;{ }^{* * *} p<.001$.

\section{DISCUSSION}

The focus of the current study was to explore the relationships among parental attachment, relational patterns, and psychological distress in college women and men. Separate multiple regression models were developed for women and men to examine relational patterns for each from the perspective of the relational-cultural model. The hypothesis that relational health and secure parental attachment would predict lower psychological distress was supported. In addition, the hypotheses that relational health would predict psychological distress beyond that accounted for by parental attachment, and that men and women would show different predictive patterns, were supported in the directions hypothesized. For women, higher scores on peer and community relational health predicted decreased psychological distress, whereas only higher community relational health scores predicted decreased psychological distress in men. This difference was also found by Frey et al. (2004) in a student clinical population (i.e., university counseling center), for which peer and community relational health were found to predict less psychological distress in women, whereas only the latter predicted less distress in men. Contrary to what has been suggested in the empirical literature, student year in school, which was entered to partial out its effect, was not a significant predictor of psychological distress, perhaps because the majority of participants were relatively early in their college years.

The results suggest that, although insecure parental attachment predicts psychological distress, authentic, empowering, and engaged peer and community relationships have a significant impact beyond that accounted for by parental attachment. These findings are congruent with assumptions of the relational-cultural model that conceptualize the developmental cycle as (a) ongoing, active, and reciprocal and (b) involving continual elaboration of be- liefs about the meaning of relationships and the actions that can be taken to influence future relational experiences (Miller \& Stiver, 1997). Thus, authentic and empowering relational connections may serve a protective function for college students in helping them cope with attachment insecurity and decreased parental emotional support.

Differing gender-related preferences in relational domains (i.e., peer, mentor, community) in the prediction of psychological distress have been supported by prior research (Frey et al., 2004; Stokes \& Levin, 1986), as previously discussed. However, these preferences may be better understood through a more detailed analysis of study findings. In women, the mean for peer relational quality was significantly higher than for men. However, the means for community relational quality were approximately equal and predicted decreased psychological distress for both groups, suggesting that both women and men seek authentic, engaged, and empowering relationships in interaction with the community. These results suggest that gender-related preferences are more complex than can be accounted for by dyadic versus group preferences or need for power versus need for intimacy, explanations which have been offered in previous research (e.g., Frey et al., 2004; Lee \& Robbins, 2000; Stokes \& Levin, 1986). Bergman (1991) stated that "... for men as well as women, there is a primary desire for connection with others ..." (p. 3). However, men are taught to prioritize self-identity and autonomy over intimacy, while, in contrast, women are taught to prioritize relational competence and intimacy because these define and shape identity (Bergman, 1991; Miller, 1986). For college men, such as those in the current study, the conflict between the need for relational quality and the need for autonomy and status may be resolved through group affiliation, which provides the status of group membership and group affirmation of skills within the college community, as 
well as a sense of belonging with reduced expectation for personal intimacy.

Community relationships were also a significant predictor for college women, but not the only significant predictor. Peer relationships were also significant, which is consistent with results from other studies (e.g., Frey et al., 2004; Rice et al., 1995; Stokes \& Levin, 1986). This pattern may serve a protective function for women in that a sense of relational quality can be gained via both peer and community relationships. Thus, college women experiencing distress within the college community may be able to turn to peer relationships to cope and women experiencing difficulty within peer relationships may be able to rely on the college community for support. Men who are experiencing difficulties within community relationships may have more limited relational alternatives.

Interestingly, mentoring relationships were not a significant predictor for women or men, although the mean score for women was significantly higher than for men. This mean score difference indicates that women, as compared to men, experienced more authentic, engaged, and empowering mentoring relationships, despite the lack of significance in predicting psychological distress. The literature indicates that strong mentoring relationships are unusual among undergraduate populations (Blackwell, 1989; Jacobi, 1989; Johnson, 1989), suggesting that this scale may not be applicable to the experience of most college undergraduates. In addition, it may be that mentoring relationships in college students, particularly those who are in the early years of college, may have more impact on achievement and academic expectations than on students' overall psychological adjustment and relational health. Because research has suggested that mentoring is important for undergraduate students (Liang et al., 2002a; Thile \& Matt, 1995) and that mentoring relationships provide the potential for authentic and mutual dyadic relationships, further research regarding the role mentoring might take in the psychological adjustment of college students is warranted.

There were some limitations to the study that must be addressed. First, the cultural diversity of the sample was limited. Although the ethnicity of the participant group was similar to the overall university population and preliminary analyses did not find effects related to ethnic group membership, it is important to note that the sample was predominantly White, with the other ethnic/racial groups consisting of relatively small numbers of participants. Similarly, the generalizability of the results to countries other than the United States, particularly those with cultures that are significantly different from U.S. culture, is unknown. Overall, future research should include exploring whether the associations among these relationships still hold with more culturally diverse samples. The available literature suggests that various relational variables have been shown to be predictive of life adjustment and/or satisfaction in, for example, African American and Asian American women (Berkel \& Constantine, 2005); international students (Hechanova-Alampay, Beehr, Christiansen, \& Van Horn, 2002); and Asian American, Korean, and Chinese students (Kang, Shaver, Sue, Min, \& Jing, 2003). These studies provide some direction for future research.

A second limitation was that it was not possible to examine subcomponents of parental attachment due to the multicollinearity within the PAQ subscales. It is possible that certain aspects of attachment (e.g., affective quality, fostering of independence or interdependence) may be more highly related to psychological distress than others. It would be interesting to explore these possibilities in future research. In addition, in view of the correlations found among the PAQ subscales, which were also found in a previous study (Kenny \& Donaldson, 1991), further examination and refinement of the PAQ may be warranted. Third, all instruments used were self-report measures and, of the three instruments, the OQ45 was the only measure on which normative data has been gathered. Thus, it is important to keep in mind that the RHI and PAQ, in particular, are subjective measures of the related constructs.

Finally, because the analyses were correlational, the reported results are associational, not causal. Although relationships similar to those found in this study were reported in a previous study (Frey et al., 2004) and the current study's design was theory-driven, definitive causal inferences cannot be drawn at this point. Although the relational-cultural model suggests that poor relational health is what leads to psychological distress, the correlational nature of the study results do not preclude the possibility that individuals experiencing distress also have interpersonal styles or relational images that negatively influence relationship building. Further research that replicates the results and examines additional variables (e.g., social skills, level of distress, quantity of support networks) would add stability to the findings.

The study results have implications for a variety of professionals working with college students. First, it would be beneficial for counselors working with students who are experiencing increased psychological distress to include interventions focused on expanding dyadic and community relational options and clarifying the roles of mutuality and authenticity in relationship development. These interventions can be implemented fairly directly via individual and group counseling with most female students. The challenges for university counseling centers in working with male students, however, include overcoming their reluctance to seek psychological help (e.g., Addis \& Mahalik, 2003; Good, Thomson, \& Brathwaite, 2005; Mahalik, Good, \& Englar-Carlson, 2003) and building therapeutic alliances with men who may be struggling with the vulnerability of dyadic relational connection (Good et al., 2005). The results of this study suggest that, for men, a focus on group counseling may be more congruent with their community orientation and may provide a gateway to individual counseling where the important longer-term goal of building dyadic relational skills (Good et al., 2005) can be addressed. Similarly, it might serve a preventive function for campus 
outreach programs to prioritize targeting the fostering of connections within the campus community. For instance, training residence hall advisors to function as liaisons between students and campus resources (e.g., cultural associations, student organizations) and teaching student organization leaders how to minimize within-group social comparison and competition would be beneficial.

Initial submission: May 4, 2005

Initial acceptance: September 21, 2005

Final acceptance: December 2, 2005

\section{REFERENCES}

Addis, M. E., \& Mahalik, J. R. (2003). Men, masculinity, and the contexts of help seeking. American Psychologist, 58, 5 14.

Ainsworth, M. D. S., Blehar, M. C., Walters, E., \& Wally, S. (1978). Patterns of attachment: A psychological study of the strange situation. Hillsdale, NJ: Erlbaum.

Allison, M. D., \& Sabatelli, R. M. (1988). Differentiation and individuation as mediators of identity and intimacy in adolescence. Journal of Adolescent Research, 3(1), 1-16.

Archer, J., \& Lamnin, A. (1985). An investigation of personal and academic stressors on college campuses. Journal of College Student Personnel, 26(3), 210-215.

Beeber, L. S. (1999). Testing an explanatory model of the development of depressive symptoms in young women during a life transition. Journal of American College Health, 47, 227-234.

Berger, J. B. (1997). Students' sense of community in residence halls, social integration, and first-year persistence. Journal of College Student Development, 38, 441-452.

Bergman, S. J. (1991). Men's psychological development: A relational perspective (Work in Progress No. 48). Wellesley, MA: Wellesley College, Stone Center.

Berkel, L. A., \& Constantine, M. G. (2005). Relational variables and life satisfaction in African American and Asian American college women. Journal of College Counseling, 8, 513.

Blackwell, J. E. (1989). Mentoring: An action strategy for increasing minority faculty. Academe, 75, 8-14.

Bowlby, J. (1982). Attachment and loss: Attachment (Vol. 1). New York: Basic Books.

Brown, L. M., \& Gilligan, C. (1992). Meeting at the crossroads. New York: Ballantine.

Chickering, A. W. (1969). Education and identity. San Francisco: Jossey-Bass.

Choi, K. (2002). Psychological separation-individuation and adjustment to college among Korean American students: The roles of collectivism and individualism. Journal of Counseling Psychology, 49, 468-475.

Cohen, J., \& Cohen, P. (1983). Applied multiple regression/ correlation analysis for the behavioral sciences (2nd ed.). Hillsdale, NJ: Erlbaum.

Dunkel-Schetter, C., \& Lobel, M. (1990). Stress among students. New Directions for Student Services, 49, 17-34.

Dwyer, A. L., \& Cummings, A. L. (2001). Stress, self-efficacy, social support, and coping strategies in university students. Canadian Journal of Counselling, 35, 208-220.
Fass, M. E., \& Tubman, J. G. (2002). The influence of parental and peer attachment on college students' academic achievement. Psychology in the Schools, 39, 561-574.

Frey, L. L., Beesley, D., \& Newman, J. L. (2005). The Relational Health Indices: Reanalysis of a measure of relational quality. Measurement and Evaluation in Counseling and Development, 38, 153-163.

Frey, L. L., Tobin, J., \& Beesley, D. (2004). Relational predictors of psychological distress in women and men presenting for university counseling center services. Journal of College Counseling, 7, 129-139.

Gilligan, C. (1982). In a different voice: Psychological theory and women's development. Cambridge, MA: Harvard University Press.

Good, G. E., Thomson, D. A., \& Brathwaite, A. D. (2005). Men and therapy: Critical concepts, theoretical frameworks, and research recommendations. Journal of Clinical Psychology, 61, 699-711.

Green, G. D. (1990). Is separation really so great? Women and Therapy, 9, 87-104.

Hagerty, B. M., Williams, R. A., Coyne, J. C., \& Early, M. R. (1996). Sense of belonging and indicators of social and psychological functioning. Archives of Psychiatric Nursing, 10(4), 235-244.

Hechanova-Alampay, R., Beehr, T. A., Christiansen, N. D., \& Van Horn, R. K. (2002). Adjustment and strain among domestic and international student sojourners: A longitudinal study. School Psychology International, 23, 458-474.

Holmbeck, G. N., \& Wandrei, M. L. (1993). Individual and relational predictors of adjustment in first-year college students. Journal of Counseling Psychology, 40, 73-78.

Jacobi, M. (1989). Student services assessment: Report on undergraduate student problems. Los Angeles: University of California, Student Affairs Information and Research Office.

Johnson, C. S. (1989). Mentoring programs. In M. L. Upcraft \& J. Gardner (Eds.), The freshman year experience: Helping students survive and succeed in college (pp. 118-128). San Francisco: Jossey-Bass.

Jordan, J. V. (1997). A relational perspective for understanding women's development. In J. V. Jordan (Ed.), Women's growth in diversity: More writings from the Stone Center (pp. 9-24). New York: Guilford.

Jordan, J. V., \& Dooley, C. (2001). Relational practice in action: A group manual. Wellesley, MA: Stone Center Publications.

Jordan, J. V., Kaplan, A. G., Miller, J. B., Stiver, I. P., \& Surrey, J. L. (Eds.). (1991). Women's growth in connection: Writings from the Stone Center. New York: Guilford.

Josselson, R. (1988). The embodied self: I and thou revisited. In D. K. Lapsley \& F. C. Power (Eds.), Self, ego, and identity: Integrative approaches (pp. 91-108). New York: Springer.

Kalsner, L., \& Pistole, M. C. (2003). College adjustment in a multiethnic sample: Attachment, separation-individuation, and ethnic identity. Journal of College Student Development, 44, 92-108.

Kang, S., Shaver, P. R., Sue, S., Min, K., \& Jing, H. (2003). Culturespecific patterns in the prediction of life satisfaction: Roles of emotion, relationship quality, and self-esteem. Personality and Social Psychology Bulletin, 29, 1596-1608.

Kenny, M. E. (1987). The extent and function of parental attachment among first-year college students. Journal of Youth and Adolescence, 16, 17-29. 
Kenny, M. E., \& Donaldson, G. A. (1991). Contributions of parental attachment and family structure to the social and psychological functioning of first-year college students. Journal of Counseling Psychology, 38, 479-486.

Kenny, M. E., \& Rice, K. G. (1995). Attachment to parents and adjustment in late adolescent college students: Current status, applications, and future considerations. The Counseling Psychologist, 23, 433-456.

Lambert, M. J., Gregersen, A. T., \& Burlingame, G. M. (2004). The Outcome Questionnaire-45. In M. E. Maruish (Ed.), Use of psychological testing for treatment planning and outcomes assessment: Volume 3. Instruments for adults (3rd ed., pp. 191-234). Mahwah, NJ: Erlbaum.

Lambert, M. J., Hansen, N. B., Umpress, V., Lunnen, K., Okiishi, J., \& Burlingame, G. M. (1996). Administration and scoring manual for the $O Q-45.2$. Stevenson, MD: American Professional Credentialing Services LLC.

Lambert, M. J., Lunnen, K., Umphress, V., Hansen, N., \& Burlingame, G. M. (1994). Administration and scoring manual for the Outcome Questionnaire (OQ-45.1). Salt Lake City, UT: IHC Center for Behavioral Healthcare Efficacy.

Lapsley, D. K., Rice, K. G., \& FitzGerald, D. P. (1990). Adolescent adjustment, identity, and adjustment to college: Implications for the continuity of adaptation hypothesis. Journal of Counseling and Development, 68, 561-565.

Lee, R. M., Keough, K. A., \& Sexton, J. D. (2002). Social connectedness, social appraisal, and perceived stress in college women and men. Journal of Counseling \& Development, 80, 355-361.

Lee, R. M., \& Robbins, S. B. (2000). Understanding social connectedness in college women and men. Journal of Counseling b Development, 78, 484-491.

Liang, B., Tracy, A. J., Taylor, C. A., \& Williams, L. M. (2002a). Mentoring college-age women: A relational approach. American Journal of Community Psychology, 30, 271-288.

Liang, B., Tracy, A., Taylor, C. A., Williams, L. M., Jordan, J. V., \& Miller, J. B. (2002b). The Relational Health Indices: A study of women's relationships. Psychology of Women Quarterly, $26,25-35$.

Lopez, F. G., \& Gormley, B. (2002). Stability and change in adult attachment style over the first-year college transition: Relations to self-confidence, coping, and distress patterns. Journal of Counseling Psychology, 49, 355-364.

Mahalik, J. R., Good, G. E., \& Englar-Carlson, M. (2003). Masculinity scripts, presenting concerns, and help seeking: Implications for practice and training. Professional Psychology: Research and Practice, 34(2), 123-131.

Mattanah, J. F., Hancock, G. R., \& Brand, B. L. (2004). Parental attachment, separation-individuation, and college student adjustment: A structural equation analysis of mediational effects. Journal of Counseling Psychology, 51, 213-225.

Miller, J. B. (1984). The development of women's sense of self (Work in Progress No. 12). Wellesley, MA: Wellesley College, Stone Center.
Miller, J. B. (1986). Toward a new psychology of women (2nd ed.). Boston: Beacon.

Miller, J. B. (1991). The development of women's sense of self. In J. V. Jordan, A. G. Kaplan, J. B. Miller, I. P. Stiver, \& J. L. Surrey (Eds.), Women's growth in connection: Writings from the Stone Center (pp. 11-26). New York: Guilford.

Miller, J. B., \& Stiver, I. P. (1997). The healing connection: How women form relationships in therapy and in life. Boston: Beacon.

Moller, N. P., Fouladi, R. T., McCarthy, C. J., \& Hatch, K. D. (2003). Relationship of attachment and social support to college students' adjustment following a relationship breakup. Journal of Counseling and Development, 81, 354-369.

Nicholas, L. (1996). Patterns of utilization of university counseling services: A comparison of a South African and a North American university. International Journal for the Advancement of Counseling, 19, 65-71.

Olson, D. A., \& Shultz, K. (1994). Gender differences in the dimensionality of social support. Journal of Applied Social Psychology, 24, 1221-1232.

Pretty, G. M. H. (1990). Relating psychological sense of community to social climate characteristics. Journal of Community Psychology, 18, 60-65.

Rice, K. G., FitzGerald, D. P., Whaley, T. J., \& Gibbs, C. L. (1995). Cross-sectional and longitudinal examination of attachment, separation-individuation, and college student adjustment. Journal of Counseling and Development, 73, 463474.

Shumaker, S. A., \& Hill, D. R. (1991). Gender differences in social support and physical health. Health Psychology, 10, 102111.

Stokes, J., \& Levin, I. (1986). Gender differences in predicting loneliness from social network characteristics. Journal of Personality and Social Psychology, 51, 1069-1074.

Surrey, J. L. (1991). The self-in-relation: A theory of women's development. In J. V. Jordan, A. G. Kaplan, J. B. Miller, I. P. Stiver, \& J. L. Surrey (Eds.), Women's growth in connection: Writings from the Stone Center (pp. 51-66). New York: Guilford.

Tabachnick, B. G., \& Fidell, L. S. (1996). Using multivariate statistics (3rd ed.). New York: HarperCollins.

Thile, E. L., \& Matt, G. E. (1995). The Ethnic Mentor Undergraduate Program: A brief description and preliminary findings. Journal of Multicultural Counseling \& Development, 23, $116-126$.

Vivona, J. M. (2000). Parental attachment styles of late adolescents: Qualities of attachment relationships and consequences for adjustment. Journal of Counseling Psychology, 47, 316-329.

Walker, M. (2004). How relationships heal. In M. Walker \& W. B. Rosen (Eds.), How connections heal: Stories from relational-cultural therapy (pp. 3-21). New York: Guilford.

Wohlgemuth, E., \& Betz, N. E. (1991). Gender as a moderator or the relationships of stress and social support to physical health in college students. Journal of Counseling Psychology, 38, 367-374. 